\title{
Evidence Based Library and Information Practice
}

\author{
Commentary
}

\section{Evidence-based Library and Information Practice: The Time is Now}

Joanne Gard Marshall

Alumni Distinguished Professor, School of Information and Library Science

University of North Carolina at Chapel Hill

Chapel Hill, North Carolina, United States of America

E-mail: $\underline{\text { marshall@ils.unc.edu }}$

(C) 2006 Marshall. This is an Open Access article distributed under the terms of the Creative Commons Attribution License (http://creativecommons.org/licenses/by/2.0), which permits unrestricted use, distribution, and reproduction in any medium, provided the original work is properly cited.

Over the last decade we have seen the concept of evidence based practice (EBP) emerge not only in the health professions but also in fields such as social work, public policy and even business. As a group that is dedicated to helping others find the information they need to do what they do better, it is high time that library and information professionals put EBP to work for themselves. But major changes in how we approach what we do take time and there are usually several inputs required before a new movement takes hold. I would argue that we are getting to the point where these inputs are accumulating and that the time is right to begin engaging in major efforts to develop, evaluate and apply our own version of EBP.

Since medicine was one of the first professions to develop and use EBP, it is not surprising that health science librarians have been in the forefront of adopting evidence based librarianship. The cost containment issues in health care generally have been strong drivers for examining current physician practices in relation to outcomes and building the scientific knowledge-base upon which to make clinical decisions. EBP is being mandated through public policy documents and various funding agencies, making the concept even more prominent. Evidence based medicine (EBM) uses a hierarchy of research design to judge the quality of evidence. As a result, a strong culture of critical appraisal of the literature, culminating in systematic reviews of existing research studies, has developed as part of EBM. Other professions have begun to develop their own versions of EBP, providing several approaches that librarians can look to as models.

We have examples of EBP from other fields, but what has been happening within librarianship itself that could be noted as steps toward adoption? A major source of leadership in Library and Information Science (LIS) resides in our professional associations. Increasingly, these associations 
are adopting statements that support doing and using LIS research, such as the Medical Library Association and the Special Libraries Association. Associations may also include research among the competencies expected of practitioners. Many LIS graduate programs include a research methods course in their curriculum and the first course specifically on evidence based librarianship was offered at the University of North Carolina at Chapel Hill in 2005-06. Research and evidence based practice are also starting to appear in library strategic planning documents.

One of the most interesting aspects of the rise of EBP in the library field has been its international nature. The first international conference was held in Sheffield, UK in 2001, the second in Edmonton, Canada in 2003, and the third in Brisbane, Australia in 2005. Starting small, the conference has essentially doubled in attendance with each successive meeting. The fourth International Conference on Evidence Based Library and Information Practice (EBLIP4) will be held in North Carolina, USA from May 6-9, 2007, with an additional two days on May 10-11 available for continuing education courses. The Australia conference was sponsored by ALIA, the Australian Library and Information Association, and brought together not only health sciences librarians but practitioners from public, academic, school and special libraries. This multisectoral interest is expected to continue.

Another sign that we are on our way towards EBP in LIS is the increasing number of publications on the topic. Andrew Booth and Anne Brice's handbook, Evidence-Based Practice for Information Professionals (2004) contains 20 chapters covering topics from why we need EBP, to appraising and applying the best available knowledge in specific areas of LIS practice such as reference, education, collection management, online searching and administration.
Increasing numbers of journal articles and conference presentations are appearing on EBP as a concept. We are also seeing an increase in the publication of research-based articles on a myriad of library topics. For several years, the Medical Library Association has required the submission of structured abstracts for its annual meeting and journal that specify the research methods used. These efforts have demonstrated the EBP is an attainable goal for library and information professionals.

So it appears that the time is right to make a major push towards evidence based practice in LIS. At the LIANZA conference in 2000, Andrew Booth defined evidence-based librarianship (EBL) as "an approach to information science that promotes the collection, interpretation, and integration of valid, important and applicable userreported, librarian-observed, and researchderived evidence. The best-available evidence moderated by user needs and preferences, is applied to improve the quality of professional judgements." While there are major challenges ahead, including developing the version of EBP that will meet our needs and building the knowledge base to support our practice, we are well positioned to move ahead. The time is now!

\section{Works Cited}

Booth, Andrew, and Anne Brice, Eds. Evidence-Based Practice for Information Professionals: A Handbook. London: Facet Publishing, 2004.

Booth, Andrew. "Exceeding Expectations: Achieving Professional Excellence by Getting Research into Practice." LIANZA Conference 2000. Christchurch, New Zealand, 2000. 3 March 2006. $<$ http://www.shef.ac.uk/ scharr/eblib/Ex ceed.pdf 